\title{
A SYSTEMATIC REVIEW OF GROUP WALKING IN PHYSICALLY HEALTHY PEOPLE TO PROMOTE PHYSICAL ACTIVITY
}

Catherine Meads

Faculty of Health, Social Care and Education, Anglia Ruskin University

catherine.meads@anglia.ac.uk

\author{
Josephine Exley \\ London School of Hygiene and Tropical Medicine
}

Background: Walking is a good way to meet physical activity guidelines. We examined the effectiveness of walking in groups compared with walking alone or inactive controls in physically healthy adults on physical activity and quality of life. (PROSPERO CRD42016033752).

Methods: We searched Medline, Embase, Cinahl, Web of Knowledge Science Citation Index, and Cochrane CENTRAL until March 2016, for any comparative studies, in physically healthy adults, of walking in groups compared with inactive controls or walking alone, reporting any measure of physical activity. We searched references from recent relevant systematic reviews. Two reviewers checked study eligibility and independently extracted data. Disagreements were resolved through discussion. Quality was assessed using likelihood of selection, performance, attrition, and detection biases. Meta-analysis was conducted using Review Manager 5.3.

Results: From 1,404 citations, 18 studies were included in qualitative synthesis and 10 in meta-analyses. Fourteen compared group walking to inactive controls and four to walking alone. Eight reported more than one measure of physical activity, none reported according to current guidelines. Group walking compared with inactive controls increased follow-up physical activity (9 randomized controlled trials, standardized mean difference [SMD] 0.58 [95 percent confidence interval \{Cl\}, 0.34-0.82] to SMD 0.43 [95 percent $\mathrm{Cl}, 0.20-0.66]$ ). Compared with walking alone, studies were too few and too heterogeneous to conduct meta-analysis, but the trend was improved physical activity at follow-up for group walking participants. Seven (all inactive control) reported quality-of-life: five showed statistically significantly improved scores.

Discussion: Better evidence may encourage government policy to promote walking in groups. Standardized physical activity outcomes need to be reported in research.

Keywords: Systematic review, Walking, Physical activity, Exercise

What is already known on this subject: The majority of people are aware that they should be more physically active but it is difficult to motivate people. Much effort has been expended by clinical public health and others to encourage people to undertake more physical activity. Walking is an excellent mode of physical activity, and more may take part if the social side of walking in groups was promoted.

What this study adds: This systematic review demonstrates that walking in groups is more effective than inactivity to increase physical activity in physically healthy people. Far less evidence is available on walking in groups compared with walking alone, but the trend was improved physical activity at follow-up for participants walking in groups.

The World Health Organisation physical activity strategy recommends that adults undertake 150 minutes of moderate aerobic physical activity, such as cycling or fast walking (35 miles per hr), or 75 minutes of vigorous activity or a mix of moderate and vigorous activity every week, plus musclestrengthening exercises on 2 or more days per week that work

Authors' contributions: C.M. developed the topic. Both authors assessed studies for inclusion, analyzed results, and wrote the manuscript. Role of funding source: Project not funded. Ethics committee approval: Not required as systematic review. all of the major muscles in the body $(1 ; 2)$. However, only a relatively small proportion of adults meet these guidelines. In the United States, in 2014, 49.2 percent adults met the physical activity guidelines for aerobic physical activity and 20.8 percent adults met the physical activity guidelines for both aerobic physical and muscle-strengthening activity (3). The equivalent proportions meeting the physical activity guidelines for aerobic physical activity are: 24 percent of men and 21 percent of women in Canada (4), 40 percent of adults in Australia (5), and 67 percent of men and 55 percent of women in the United Kingdom (6).

Dropout rates for exercise initiatives are known to be high $(7 ; 8)$. However, there is good evidence that exercise adherence is enhanced through the use of social support $(9 ; 10)$. A recent mixed-methods systematic review on community-based group exercise interventions for older adults found that increased social connectedness, wellbeing gains, and an empowering environment were themes associated with above average long-term adherence rate (11). This study concluded that incorporating participants' views into exercise program designs could provide guidance for innovative interventions, which would lead to sustained adherence.

Walking is a highly accessible form of physical activity and is associated with a range of positive health benefits $(12 ; 13)$. 
Governments have strongly encouraged the public to increase physical activity through walking. For example, the U.K. government aimed to invest $£ 7$ million between 2008 and 2011 in a program of innovative campaigns to encourage people to walk more $(14 ; 15)$, and the U.S. Department of Health and Human Services advocates walking as the principle component of its Active Living (16;17) initiative (one of seven priorities in the National Prevention Strategy) (18). And, as mentioned above, the World Health Organization physical activity recommendations include walking.

There have been three recent systematic reviews evaluating the effectiveness of walking groups to enhance health (19) and increase physical activity $(20 ; 21)$. They included forty-two studies (19), nineteen studies (20), and ten studies (in the led walks section) (21), and all have strengths and weaknesses. For example, two $(19 ; 20)$ included both randomized and nonrandomized studies, but the other (21) included randomized controlled trials (RCTs) only. All three included studies with physically and/or mentally healthy participants and studies with participants with a variety of physical conditions that may impede walking (such as knee osteoarthritis), and did not metaanalyze results for different participant groups separately. Also studies included in earlier systematic reviews were not included in later systematic reviews. One (20) included more than one effect size estimate per study, thus double counting results from some participants. One (21) did not conduct meta-analyses, and one (19) had a physical functioning (6-min walk test) metaanalysis of two included studies in nonhealthy patients. None of the reviews looked at the specific impact that being part of a group had on adherence to the intervention.

This systematic review evaluates the effectiveness in physically healthy adults of walking in groups compared with inactive controls and/or individuals walking alone, focusing on any measure of physical activity or quality of life at follow-up. By also including walking alone as a comparison group, we examine whether being part of a group is more likely to lead to greater benefits than walking alone.

\section{METHODS}

We developed and registered a protocol for this systematic review (Prospero registration number CRD 42016033752). The predefined inclusion criteria were comparative group studies in any language with physically healthy adults taking part in led walks or community group walks with an aspect of social interaction in addition to walking. We defined physically healthy as free from reported physical conditions or pain that would impede walking. We accepted a maximum of 20 percent in any group with pre-existing physical conditions so as not to exclude useful information, because many participants were likely to be older and not all would be completely physically healthy. Any forms of walking groups were compared with either (a) standard care, waiting list or any other nonactive interventions such as physical activity advice or lectures on diet or nutrition (Set 1), or (b) walking alone (Set 2). Outcomes of interest were any measure of physical activity at follow-up and/or any measure of generic quality of life or wellbeing. Outcomes could be measured at any time at or after the end of the intervention.

The following databases were searched between 2010 and March 2016: Medline, Embase, Cumulative Index to Nursing and Allied Health Literature (CINAHL), Cochrane Central and Web of Science, Science Citation Index. Search terms included walk*, groups, program*, club, community, healthy, physical activity and exercise. Both MESH terms and keywords were used (see Supplementary Table 1). Search terms were piloted to ensure that searches were sufficiently sensitive to find known includable studies. Reference lists of included studies and systematic reviews (19-21) were checked for includable studies. Because there had been three relevant published systematic reviews with very comprehensive searches, with dates up to 2011-12, our searches were started in 2010 to ensure no studies were missed during the overlapping period. All relevant titles and abstracts were transferred to Endnote for assessment.

Two reviewers (C.M. and J.E.) checked study eligibility independently. Both also independently extracted data from studies into standardized, predesigned extraction tables in Microsoft Word. Disagreements were resolved through discussion. Quality of included studies was assessed using likelihood of selection, performance, attrition, and detection biases because of the variety of study designs included. Specific quality checklists evaluate these biases tailored to different study designs and as we had a variety of study designs included, going back to fundamental quality assessment was considered to be more useful than using a mixture of different checklists.

We tabulated the characteristics and results of all the included studies; analysis was quantitative. Numerical results were presented as point estimates of effect sizes (means, medians) with any reported measures of spread (standard deviations, standard errors, ranges, confidence intervals). Where standard errors, ranges, or 95 percent confidence intervals (CIs) were provided, standard deviations were calculated using standard formulae from the Cochrane Handbook (22). Review Manager (version 5.3, The Cochrane Library) was used for metaanalyses. Where medians and ranges were given, these were only converted into means and SDs if the ranges were not skewed. We used random effects models because of heterogeneity of participants, interventions, and outcome measures of physical activity. Where categorical measures were reported, meta-analyses used odds ratios (OR). Most outcomes, however, were continuous measures, and we used standardized mean differences (SMD) as outcomes had differing measurement scales.

In one of the continuous outcome measures, a lower score was a better result (time taken to walk 1 mile), so these results were reversed for the meta-analysis. Several of the studies had more than one measure of physical activity, so we conducted two continuous measures meta-analyses, one using the lowest 
values (smallest effect size) and one using the highest values (largest effect size). Where only one measure of physical activity was reported this is used in both meta-analyses. There was insufficient evidence to warrant further investigation of heterogeneity by meta-regression. Risk of publication bias was assessed using a funnel plot.

\section{Role of the Funding Source}

There was no funding source for this study. The corresponding author had full access to all the data in the study and had final responsibility for the decision to submit for publication.

\section{RESULTS}

Searches found 1,404 titles and abstracts. After removing duplicates, 1,047 remained for screening, of which 1,000 were excluded. Full papers for seventy-nine articles were assessed for inclusion (forty-seven from database searches and thirtytwo from reference lists) (see Supplementary Figure 1). For a full list of excluded studies and reasons for exclusion, see Supplementary Table 2 . There were eighteen studies included in the qualitative synthesis: fourteen used an inactive control (Set 1) (23-36) and four compared group walking interventions to walking alone (Set 2) (37-40). One study from Set 1 (30) had a second publication reporting long-term follow-up (41). There were ten studies from Set 1 in the quantitative syntheses (metaanalyses). It is possible that there might be an effect from publication bias suggesting that small trials with no significant effects have not been published, or their physical activity results not published (see Supplementary Figure 2).

Characteristics of included studies are presented in Supplementary Table 3 . The majority of studies (14 of 18) were RCTs or cluster RCTs; there was also one nonrandomized experimental study (36), two case-control $(38 ; 39)$ and one cohort study with a local population comparator (29). The number of participants in studies varied between 17 and 605 participants; seven of the studies had fewer than 50 participants. Most studies included older participants (older than 65 years) but participants' ages ranged from 18 to 91 years. Participants were community volunteers in eight studies $(23 ; 24 ; 26 ; 32-34 ; 36 ; 37)$; recruitment was by means of general practices or community centers in six studies $(25 ; 27 ; 31 ; 35 ; 38 ; 40)$, from specific housing areas in two studies $(29 ; 39)$, and from random population sampling in one study (28). In the remaining study, the recruitment method was unclear (30).

The interventions were all led walks or walking in groups. In some studies, the intervention consisted of encouraging participants to walk in a group, facilitated by advertising locally and training an individual to lead the walks, in others the intervention entailed leading the group in the walks. Interventions studied lasted between 5 and 90 minutes on 1 to 7 days per week, for between 8 weeks and 1 year. The frequency and du- ration of walking was tailored to the ages of the sample participants.

The comparators in Set 1 were usual activities, cancer screening, fitness testing, advice, educational lectures, no walking group encouragement, waiting list, no intervention, routine care or unspecified inactive controls. The comparators in Set 2 were usual care with encouragement to walk but no access within the study to a walking group $(27 ; 28)$, being a former walking club member but still walking (39), and not being paired with a "buddy" to walk with (40). Follow-up was at the end of the intervention only for most of the studies, three studies had additional follow-ups at between 3 months and 10 years $(23 ; 27 ; 30)$. One case-control study (39) had no followup, as the comparator was retrospective. Outcomes measured were of a wide variety of categorical and continuous physical activity measures; no study used the same physical activity measure.

Quality of included studies varied (see Supplementary Table 4); nine studies were classified as being at high risk of bias and five medium and four low risk of bias. Several of the studies gave insufficient details to assess all aspects of quality, so classification may not be accurate. An intervention such as this cannot be blinded to the participant, but blinding of investigators and outcome assessment should have been possible, but it was not apparent whether this had been done in the majority of the studies (24-26;28;33-35;36;38-40). For the cluster RCTs, in Thomas et al. (40), it was clear that participants knew they were part of a trial, whereas in Fisher and Li (24) and Jancey et al. (28), this was unclear.

\section{Physical Activity Outcomes}

Numerical results are shown in Table 1. For Set 1 (inactive controls), meta-analysis of the continuous measure of physical activity showed that walking in groups increased physical activity at follow-up compared with inactive controls (nine RCTs, highest value SMD 0.58 [95 percent CI, 0.34-0.82; $\mathrm{I}^{2}=76$ percent] and lowest value SMD 0.43 [95 percent CI, 0.20-0.66; $\mathrm{I}^{2}=73$ percent]) (see Figure 1a and b). Removing the nonrandomized experimental study (36) reduced the SMD from 0.58 (95 percent CI, 0.34-0.82) to 0.51 (95 percent CI 0.28 to 0.74) (36).

When the two studies that undertook follow-up beyond the end of the intervention (22 months and 3.5 months after participating in intervention) $(27 ; 30)$ are taken out of the lowest value meta-analysis, the SMD increases from 0.43 (95 percent CI, 0.20 to 0.66 ) to 0.66 (95 percent CI, 0.30 to 1.02 ), suggesting that physical activity gains associated with participating in walking groups diminished over time $(27 ; 30)$. Two studies measured categorical outcomes for physical activity. The metaanalysis found that the risk of participants being physically active at the end of the intervention was significantly higher in the intervention group compared with the comparators (relative 
Table 1. Numerical Physical Activity Results

\begin{tabular}{|c|c|c|c|c|c|c|c|}
\hline \multirow[b]{2}{*}{ Study } & \multirow[b]{2}{*}{ Intervention N } & \multirow[b]{2}{*}{ Control $N$} & \multirow[b]{2}{*}{ Physical activity measure } & \multicolumn{2}{|c|}{ Follow up 1} & \multicolumn{2}{|c|}{ Follow up 2 (if reported) } \\
\hline & & & & Intervention & Control & Intervention & Control $N$ \\
\hline \multicolumn{8}{|c|}{ Inactive controls } \\
\hline $\begin{array}{l}\text { Avila and Hovell } 1994 \\
(23)^{a}\end{array}$ & $N=22$ & $N=22$ & Exercise frequency & NR* & NR* & NR & NR \\
\hline $\begin{array}{l}\text { Hamdorf and Penhall } \\
1999 \text { (26) }\end{array}$ & $N=18$ & $N=20$ & $\begin{array}{l}\text { Maximum current activities (mean (SE)), i.e., } \\
\text { highest current activity }\end{array}$ & $\begin{array}{l}72.3(1.82)^{*} \\
(S D 7.72)^{b}\end{array}$ & $\begin{array}{l}61.3(2.07)^{*} \\
(S D 9.26)^{b}\end{array}$ & $\mathrm{~N} / \mathrm{A}$ & $\mathrm{N} / \mathrm{A}$ \\
\hline \multirow[t]{3}{*}{ Isaacs et al. 2007 (27) } & $N=300$ & $N=305$ & $\begin{array}{l}\text { Minutes of MVPA (adjusted geometric mean } \\
\text { relative to baseline }(95 \% \mathrm{Cl}) \text { ) }\end{array}$ & $\begin{array}{l}89(95 \% \mathrm{Cl}, \\
75-106) \\
(S D 136.97)^{b}\end{array}$ & $\begin{array}{l}58(95 \% \mathrm{Cl} \\
49-69) \\
(S D 89.10)^{b}\end{array}$ & $\begin{array}{l}128(95 \% \mathrm{Cl} \\
109-151)\end{array}$ & NR \\
\hline & & & $\begin{array}{l}\text { Total minutes of activity (adjusted geometric } \\
\text { mean relative to baseline }(95 \% \mathrm{Cl}) \text { ) }\end{array}$ & $\begin{array}{l}759(703-820) \\
(S D 516.96)^{b}\end{array}$ & $\begin{array}{l}647(600-699) \\
\text { SD } 441.06)^{b}\end{array}$ & $\begin{array}{l}907(95 \% \mathrm{Cl} \\
841-977)\end{array}$ & NR \\
\hline & & & $\begin{array}{l}\text { Energy expenditure per week (adjusted } \\
\text { geometric mean relative to baseline } \\
(95 \%(\mathrm{I}))\end{array}$ & $\begin{array}{l}42(39-45) \\
(S D 26.51)^{b}\end{array}$ & $\begin{array}{l}35(33-38) \\
(S D 22.28)^{b}\end{array}$ & $\begin{array}{l}49(95 \% \mathrm{Cl}, \\
45-52)\end{array}$ & NR \\
\hline Jancey et al. 2008 (28) & $N=177$ & $N=236$ & Total physical activity times (mean (SD)) & $6.20(5.01)$ & $5.29(6.19)$ & $\mathrm{N} / \mathrm{A}$ & $\mathrm{N} / \mathrm{A}$ \\
\hline \multirow{3}{*}{ Krieger et al. 2009 (29) } & $N=53$ & $N=155$ & Minutes walked per day (mean (SD)) & 108.8 (NR) & 64.2 (NR) & N/A & $\mathrm{N} / \mathrm{A}$ \\
\hline & & & $\begin{array}{l}\text { Minutes walked per day for exercise, (Mean } \\
\text { (SD)) }\end{array}$ & 51.0 (NR) & 26.7 (NR) & N/A & $\mathrm{N} / \mathrm{A}$ \\
\hline & & & $\begin{array}{l}\text { Percentage doing moderate activity at least } \\
150 \mathrm{mins} / \text { week }\end{array}$ & $80.8 \%$ & $56.3 \%$ & $\mathrm{~N} / \mathrm{A}$ & $\mathrm{N} / \mathrm{A}$ \\
\hline \multirow[t]{4}{*}{$\begin{array}{l}\text { Kriska et al. } 1986 \text { (30) } \\
\text { (Pereira et al. } 1998 \text { (41)) }\end{array}$} & $N=114$ & $N=115$ & $\begin{array}{l}\text { Blocks (urban environment) walked daily } \\
\text { (Mean (SD)) }\end{array}$ & $15.54(11.01)^{*}$ & $10.56(9.33)^{*}$ & $16.33(9.88)^{*}$ & $9.56(8.76)^{*}$ \\
\hline & & & Flights of stairs climbed/day (mean (SD)) & $9.91(7.36)$ & $9.6(9.86)$ & $9.22(7.71)$ & $8.94(6.23)$ \\
\hline & & & LSI Activity Monitor day count/hr (mean (SD)) & $47.32(35.47)^{*}$ & $37.22(22.96)^{*}$ & $47.16(29.47)^{*}$ & $37.46(21.14)^{*}$ \\
\hline & & & $\begin{array}{l}\text { LSI Activity Monitor evening count/hr (mean } \\
\text { (SD)) }\end{array}$ & $25.8(19.83)$ & $22.16(17.33)$ & $24.88(22.85)$ & $24.88(28.96)$ \\
\hline \multirow[t]{3}{*}{ Lamb et al. 2002 (31) } & $N=95$ & $N=93$ & Numbers active & $20(21.1 \%)$ & $20(21.5 \%)$ & $37(38.9 \%)$ & $25(28.9 \%)$ \\
\hline & & & Walking mins/wk (median (IQR)) & $60(0-120)$ & $30(0-150)$ & $60(0-197.5)$ & $60(0-180)$ \\
\hline & & & Walking sessions/wk (median (IQR)) & $2.5(0-6)$ & $2(0-3)$ & $\begin{array}{l}4.0(0-8) \\
(S D 6)^{b}\end{array}$ & $\begin{array}{l}2.5(0-6) \\
(S D 4.5)^{b}\end{array}$ \\
\hline
\end{tabular}


Table 1. Continued

\begin{tabular}{|c|c|c|c|c|c|c|c|}
\hline \multirow[b]{2}{*}{ Study } & \multirow[b]{2}{*}{ Intervention $N$} & \multirow[b]{2}{*}{ Control $N$} & \multirow[b]{2}{*}{ Physical activity measure } & \multicolumn{2}{|c|}{ Follow up 1} & \multicolumn{2}{|c|}{ Follow up 2 (if reported) } \\
\hline & & & & Intervention & Control & Intervention & Control $N$ \\
\hline \multirow[t]{2}{*}{ Maki et al. 2012 (32) } & \multirow[t]{2}{*}{$N=66$} & \multirow[t]{2}{*}{$N=67$} & $\begin{array}{l}\text { Life space assessment questionnaire (Mean } \\
\text { (SD)) }\end{array}$ & $101.1(15.4)$ & $95.9(18.0)$ & \multirow[t]{2}{*}{$\mathrm{N} / \mathrm{A}$} & \multirow[t]{2}{*}{$\mathrm{N} / \mathrm{A}$} \\
\hline & & & $\begin{array}{l}\text { Average number of pedometer steps (Mean } \\
\text { (SD)) }\end{array}$ & 7044 (2891)* & $4940(2552)^{*}$ & & \\
\hline Palmer 1995 (34) & $N=16$ & $N=11$ & $\begin{array}{l}\text { Mile walk times (NB lower number better) } \\
\text { (Mean (SD)) }\end{array}$ & $17.6(0.6)$ & $19.7(1.8)$ & $\mathrm{N} / \mathrm{A}$ & N/A \\
\hline \multirow[t]{2}{*}{ Resnick 2002 (35) } & \multirow[t]{2}{*}{$N=10$} & \multirow[t]{2}{*}{$N=7$} & $\begin{array}{l}\text { Exercise activity (total number of hours) (Mean } \\
\text { (SD)) }\end{array}$ & $14.1(9.6)^{*}$ & $0.0(0.0)^{*}$ & $\mathrm{~N} / \mathrm{A}$ & N/A \\
\hline & & & Overall activity (kcals per week) (Mean (SD)) & $31.9(19.4)$ & $18.4(15.4)$ & $\mathrm{N} / \mathrm{A}$ & $N / A$ \\
\hline \multirow[t]{2}{*}{$\begin{array}{l}\text { Takahashi et al. } 2013 \\
\text { (36) }\end{array}$} & \multirow[t]{2}{*}{$N=14$} & \multirow[t]{2}{*}{$N=14$} & $\begin{array}{l}\text { MVPA (by accelerometer) not on WG } \\
\text { days(Mean (SD)) }\end{array}$ & $165.2(20.4)$ & $136.6(16.9)$ & N/A & N/A \\
\hline & & & MVPA (accelerometer) (Mean (SD)) & $235.5(14.3)$ & $136.6(16.9)$ & $\mathrm{N} / \mathrm{A}$ & N/A \\
\hline \multirow{2}{*}{$\begin{array}{l}\text { Walking alone controls } \\
\text { Cox et al. } 2008 \text { (37) }\end{array}$} & \multirow[b]{2}{*}{$N=27$} & \multirow[b]{2}{*}{$N=22$} & \multirow[b]{2}{*}{ 1.6km walk time (NB lower number better) } & \multirow[b]{2}{*}{$13.91(S D=1.02)$} & \multirow[b]{2}{*}{$13.77(S D=0.94)$} & & \\
\hline & & & & & & $\begin{array}{l}14.17 \\
(1.03) \\
(N=22)\end{array}$ & $\begin{array}{l}13.57 \\
(1.01) \\
(N=20)\end{array}$ \\
\hline \multirow[t]{2}{*}{ Lee et al. 2011 (38) } & \multirow[t]{2}{*}{$N=22$} & \multirow[t]{2}{*}{$N=27$} & Exercise duration (mins/day) & 66.0 (NR)* & $45.24(\mathrm{NR}) *$ & N/A & $\mathrm{N} / \mathrm{A}$ \\
\hline & & & Exercise frequency (times/wk) & 4.27 (NR)* & 3.78 (NR)* & $\mathrm{N} / \mathrm{A}$ & N/A \\
\hline Nguyen et al. 2002 (39) & $N=267$ & $N=236$ & Percentage walking $1 \mathrm{~km}$ or less & $82.8 \%$ & $50.0 \%$ & $\mathrm{~N} / \mathrm{A}$ & $N / A$ \\
\hline Thomas et al. 2012 (40) & $N=193$ & $N=206$ & $\begin{array}{l}\text { Physical activity/ fitness (IPAQ } 1000 \text { MET } \\
\text { minutes per week) (differences in means } \\
\text { compared to controls) }\end{array}$ & $\begin{array}{l}1.26 \\
(95 \% \mathrm{Cl}=0.78-1.74)\end{array}$ & (group results NR) & N/A & N/A \\
\hline
\end{tabular}

${ }^{*} p=0.05$ or less.

aDetails from Blank et al. (21).

bestimated values for SD.

CI, confidence interval; IPAQ, International Physical Activity Questionnaire; IQR, inter-quartile range; kcal, kilocalories; km, kilometre; LSI, Large Scale Integrated; MET, metabolic equivalent; mins, minutes; MVPA, moderate or vigorous physical activity; NB, nota bene; NR, not reported; N/A, not applicable; SD, standard deviation; SE, standard error; WG, walking group; wk, week. 


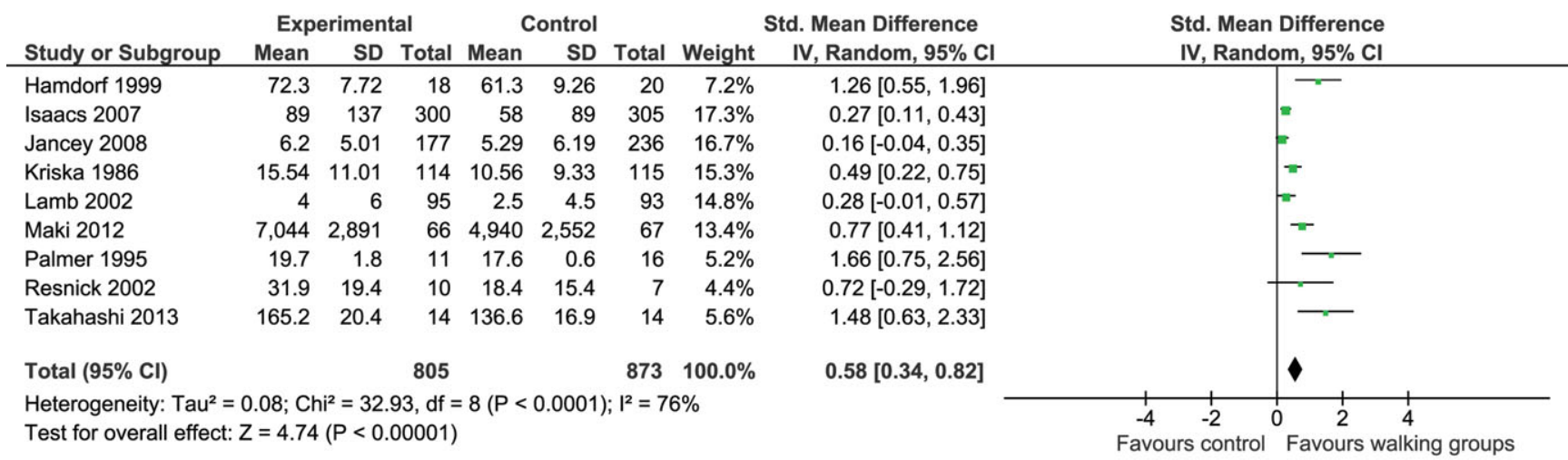

Figure 1. a: Meta-analysis of continuous physical activity outcomes (higher values).

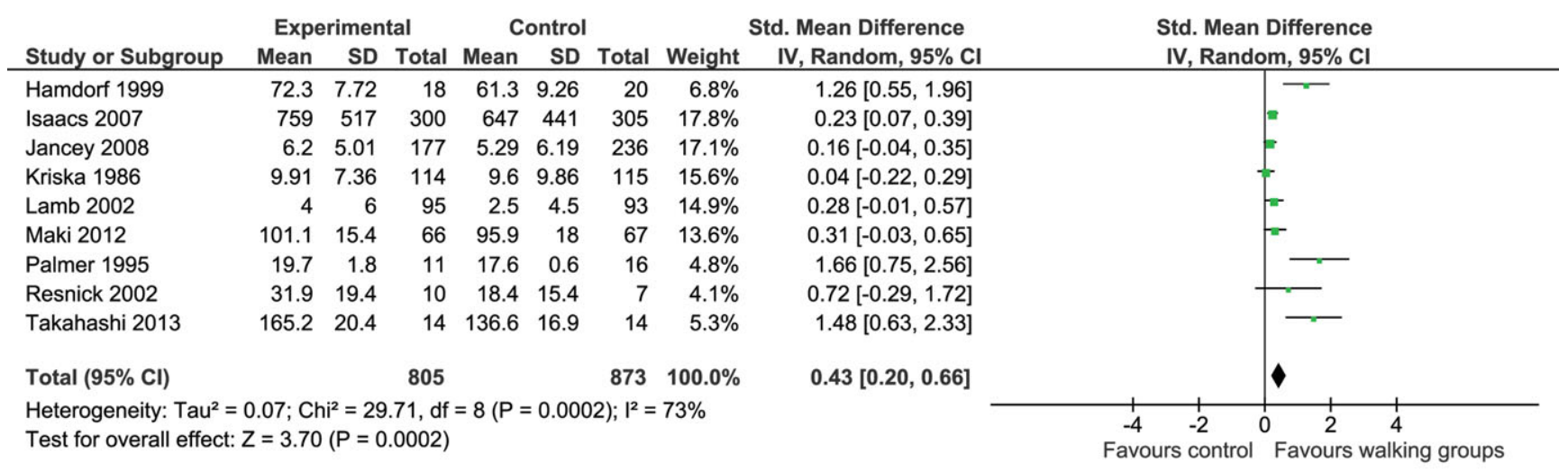

Figure 1. b: Meta-analysis of continuous physical activity outcomes (lower values).

risk 1.44 [95 percent CI, 1.22-1.70; $\mathrm{I}^{2}=0$ percent]) (Supplementary Figure 3).

For Set 2 (walking alone controls), studies were too few and too heterogeneous to conduct meta-analysis. For Cox et al. (37), there was no difference in $1.6 \mathrm{~km}$ walk time between intervention and control groups at both 6 months and 1 year follow-ups. In Lee et al. (38), exercise frequency and duration were statistically significantly improved for the intervention group compared with controls at the end of the intervention (12 weeks). For Nguyen et al. (39), there was a higher percentage of participants walking $1 \mathrm{~km}$ or less in the intervention group compared with the controls. In Thomas et al. (40), those receiving the buddy intervention had higher mean physical activity levels at 12 months than controls, although the numerical results for the control group were not explicitly reported.

\section{Quality of Life Outcomes}

Seven of the Set 1 and none of the Set 2 studies measured quality of life and wellbeing (see Table 2). Studies used a variety of measures for quality of life and wellbeing including Euroqol EQ-5D, Nottingham Health Profile (NHP), SF36, and SF-12. All scores except NHP had higher scores indicating better quality of life. For NHP, higher scores indi- cated greater number and severity of problems. In five of the seven studies (24-26;32;33), the walking group intervention groups showed statistically significantly improved scores compared with controls in at least one of the outcomes measured. In the remaining two studies $(27 ; 35)$, there were no significant differences found, including in NHP scores. None of the outcomes measured showed significantly worse quality of life or wellbeing for the walking group interventions compared with controls.

\section{Other Outcomes}

Retention rates are shown in Supplementary Table 4 and include retention rates for all participants, or retention rates by group where reported. Ten of the studies reported retention rates separately for the intervention groups compared with controls (eight in Set 1 and two in Set 2). Seven had higher rates for the intervention groups, whereas three had higher rates for the control groups. In several instances, the rates were very similar. Many of the studies found that retention rates dropped gradually over time. There was insufficient information to determine whether different types of control had any impact on retention rates. 
Table 2. Quality of life and wellbeing results (all self-report)

\begin{tabular}{|c|c|c|c|c|c|c|}
\hline Study & Intervention N & Control N & Quality of life measure & Intervention & Control & Significance testing \\
\hline \multirow[t]{3}{*}{ Fisher and Li 2004 (24) } & $N=224$ & $N=358$ & SF-12 physical & $72.32(28.49)$ & $62.90(25.55)$ & $p<0.001$ \\
\hline & & & SF-12 mental & $72.46(23.86)$ & $66.99(24.07)$ & $p<0.05$ \\
\hline & & & Satisfaction With Life scores & $16.05(3.69)$ & $15.16(3.77)$ & $p=0.05$ \\
\hline \multirow[t]{2}{*}{ Gusi et al. 2008 (25) } & $N=55$ & $N=51$ & $\begin{array}{l}\text { Anxiety/depression by EQ-5D } \\
\text { (mean (SD)) }\end{array}$ & $1.2(0.4)$ & $1.4(0.6)$ & $p=0.009$ \\
\hline & & & $\begin{array}{l}\text { EQ-5D (mean (SD) ANCOVA and } \\
\text { adjusted for baseline) }\end{array}$ & $0.890(0.178)$ & $0.510(0.196)$ & NR \\
\hline \multirow[t]{2}{*}{$\begin{array}{l}\text { Hamdorf and Penhall } \\
1999 \text { (26) }\end{array}$} & $N=18$ & $N=20$ & $\begin{array}{l}\text { Nottingham Health Profile at } 6 \\
\text { months }\end{array}$ & NR & NR & $p=N S$ \\
\hline & & & $\begin{array}{l}\text { Modified Philadelphia Geriatric } \\
\text { Centre Morale scale (mean } \\
\text { (SE)) }\end{array}$ & $9.9(0.38)$ & $7.8(0.58)$ & $p=0.002$ \\
\hline \multirow{2}{*}{$\begin{array}{l}\text { Isaacs et al. } 2007 \\
(27)^{*}\end{array}$} & $N=300$ & $N=305$ & SF-36 (mean (SD)) & $0.75(0.14)$ & $0.75(0.14)$ & $p=\mathrm{NS}$ \\
\hline & & & Euroqol questionnaire & NR & NR & $\begin{array}{l}\text { No differences } \\
\text { between treatment } \\
\text { groups or between } \\
\text { during the trial and } \\
\text { follow-up }\end{array}$ \\
\hline Maki et al. 2012 (32) & $N=75$ & $N=75$ & $\begin{array}{l}\text { Satisfaction in Daily Life } \\
\text { questionnaire }\end{array}$ & $45.3(4.4)$ & $44.5(5.8)$ & $\begin{array}{l}\text { Before-after interaction } \\
\quad p=0.002\end{array}$ \\
\hline \multirow[t]{8}{*}{$\begin{array}{l}\text { Moore-Harrison et al. } \\
2008 \text { (33) }\end{array}$} & $N=12$ & $N=12$ & $\begin{array}{l}\text { SF-36 physical functioning } \\
\text { (mean (SD)) }\end{array}$ & $85.8(13.6)$ & $69.6(18.3)$ & $p=0.014$ \\
\hline & & & $\begin{array}{l}\text { SF-36 role-physical (mean } \\
\text { (SD)) }\end{array}$ & $81.3(21.7)$ & $85.4(16.7)$ & $p=\mathrm{NS}$ \\
\hline & & & SF-36 bodily pain (mean (SD)) & $69.3(25.2)$ & $61.9(19.7)$ & $p=\mathrm{NS}$ \\
\hline & & & $\begin{array}{l}\text { SF-36 general health (mean } \\
(\text { SD)) }\end{array}$ & $74.8(13.1)$ & $74.3(11.8)$ & $p=N S$ \\
\hline & & & SF-36 vitality (mean (SD)) & $66.7(15.1)$ & $66.3(12.6)$ & $p=N S$ \\
\hline & & & $\begin{array}{l}\text { SF-36 social functioning (mean } \\
\text { (SD)) }\end{array}$ & $89.6(14.9)$ & $92.7(15.5)$ & $p=N S$ \\
\hline & & & $\begin{array}{l}\text { SF-36 role-emotional (mean } \\
\text { (SD)) }\end{array}$ & $83.3(33.3)$ & $88.9(21.7)$ & $p=N S$ \\
\hline & & & $\begin{array}{l}\text { SF-36 mental health (mean } \\
\text { (SD)) }\end{array}$ & $82.0(12.9)$ & $87.3(6.8)$ & $p=N S$ \\
\hline \multirow[t]{2}{*}{ Resnick 2002 (35) } & $N=10$ & $N=7$ & $\begin{array}{l}\text { SF-12 physical health (mean } \\
\text { (SD)) }\end{array}$ & $47.0(5.2)$ & $46.8(3.2)$ & $p=N S$ \\
\hline & & & $\begin{array}{l}\text { SF-12 mental health (mean } \\
\text { (SD)) }\end{array}$ & $33.4(4.8)$ & $31.2(4.9)$ & $p=N S$ \\
\hline
\end{tabular}

*Follow up 2 reported for intervention group only $N=300$, SF-36 mean $(S D)=0.77$ (0.15), Abbreviations: EQ-5D - Eurogol 5 Dimensions, NR - not reported, NS - no significant difference between groups, SD - standard deviation, SE - standard error, SF - short form

Scale ranges - SF-12 - range 0 to 100 for physical and mental health components, where a zero score indicates the lowest level of health and 100 indicates the highest level of health. Satisfaction with Life - range 5 to 35, with a score of 20 representing neutral and between 5-9 indicating extreme dissatisfaction with life, and between 31-35 indicating extreme satisfaction. EQ-5D (Eurogol) - range 0 to 1 where 0 is death and 1 is perfect perceived health. Nottingham Health Profile - range 2 to 200 where the higher the score, the greater the number and severity of problems. Modified Philadelphia Geriatric Centre Morale scale - range 0 to 17 where a higher score indicates higher morale, Satisfaction in Daily life - range unavailable but higher score indicates better quality of life, SF-36 - range 0 to 100 for eight scales where a zero score indicates the lowest level of health and 100 indicates the highest level of health. 
Three studies in Set 1 and no studies in Set 2 reported numerical results for measures of social network or sociableness. Jancey et al. (28) used a categorical measure of "Having no friends nearby" in Generalized Estimating Equations and found that it had a significant negative effect $(p=.037)$ on total physical activity times, suggesting that fewer friends nearby was correlated with less total physical activity. Krieger et al. (29) measured the number of neighbors the participant knew well enough to say hello to. They reported before and after results for the intervention group only and found a significant increase in the mean number of neighbors that participants knew well enough to say hello to while walking (4.3 [95 percent CI, 2.0-6.7] $p=.001$ ). Maki et al. (32) measured the Lubben Social Network Scale and found that there was no significant difference in mean scores between the intervention and control groups (16.3 [SD 5.7] versus 16.8 [SD 5.2] $p=.16$ ).

\section{DISCUSSION}

\section{Main Findings}

The main finding was that physical activity in physically healthy adults improved at follow-up for the walking group intervention compared with inactive controls. This is based mostly on self-report physical activity outcomes, and only one study used accelerometry (36), but this study was small, with fourteen participants in each group. This physical activity improvement was strongest immediately following completion of the intervention and reduced somewhat at longer follow-ups. Walking in groups tended to increase quality of life measures and may increase social connectedness, but the evidence for this was uncertain. There was insufficient evidence to indicate whether walking in groups was more effective than walking alone for increasing physical activity and no evidence on the impact on quality of life.

Retention rates tended to be higher in the intervention groups. No included study reported the proportion of participants meeting the recommended guidelines for physical activity of 30 minutes moderate intensity physical activity five times per week (42). In general, the quality of the evidence found was mixed, with seven of thirteen studies in Set 1 and two of four studies in Set 2 considered to be at high risk of bias.

\section{Comparison to Previous Work}

Previous systematic reviews found that walking groups, compared with a variety of active and inactive controls provided wide-ranging health benefits (19) and that they were effective in increasing physical activity (20), including for leisure and travel (21). However, this is the first systematic review to quantify this effect in physically healthy people compared with inactive controls through meta-analyses. Also, this is the first systematic review to attempt to compare the sociable side of walking in groups to people walking alone.

\section{Strengths and Limitations}

This systematic review has several strengths in that it is both more comprehensive than previous systematic reviews as it included adult participants of any ages, and more focused as it only included mainly physically healthy participants, rather than mixing participants with conditions likely to impede the ability to walk, such as knee arthritis, with participants without such difficulties. In the included studies, participants varied but were mostly older adults, particularly older women and it is women in the age group of 55- to 74-year-olds that form the majority of walkers in walking groups (43). As many participants were older, not all will be completely physically healthy, so a pragmatic decision was made to limit the proportion of physically unhealthy participants in any group to 20 percent or less, so as not to exclude useful information.

Extensive searches of reference lists from previous systematic reviews, included studies and policy documents were made, in addition to database searches, to find all eligible studies. All included studies were listed in one or more of the three systematic reviews (19-21). It is clear from the fact that the previously published systematic reviews (19-21) were not comprehensive that searching for these types of studies is not straightforward. One reason is that, when searching for studies, the term "walking group" can refer to one arm of a comparative study rather than where people were walking in groups. Therefore, a relatively large number of full texts were read thoroughly to ascertain the exact nature of the walking intervention and whether it had any kind of social interaction. Physical activity interventions are difficult to search for by means of databases alone, for example another systematic review of physical activity interventions found twice as many studies by means of other sources than by means of database searches (44). Also definitions of physical activity, exercise, and physical fitness can vary, so in this study, we use descriptions defined by Caspersen et al. (45).

There were some studies where full papers were unavailable that could have been includable in the systematic review. Every effort was made to use all available data including extracting information from existing systematic reviews. The included studies were very heterogeneous in terms of participants, interventions, comparators, follow-up lengths, and study designs, so it could be argued that studies should not have been meta-analyzed. Also, some studies had imbalances at the start of the study, for example, the cluster RCT by Jancey et al. (28). However, random effects models were used to mitigate these factors to some extent, but this gives more weight to smaller studies than fixed effects meta-analysis. Given that most of the included studies were relatively small, this weighting may be a strength rather than a weakness.

We included any comparative studies rather than RCTs only, and it could be argued that the different study designs should not have been meta-analyzed. Also no two physical activity outcomes were the same. Most were by self-report, which can be inaccurate; few used objective measures; and only one 
used accelerometry (36). However, they were all measuring physical activity in some way, which meant that they could be meta-analyzed. This approach assumes that an SD change in one physical activity measurement scale is equivalent to an SD change on another, which may not be true. Some numerical results were missing, which meant that not all studies could be entered in the meta-analyses. We had to estimate SD from other measures of spread in three studies $(26 ; 27 ; 31)$, but in one other (29), there was no measure of spread given, so it could not contribute to the meta-analysis result. Because of all these factors, we consider our meta-analyses exploratory, and we conducted sensitivity analyses by altering the physical activity outcomes entered into the meta-analyses to generate highest and lowest effect size estimates.

We did not include the time spent in physical activity in the meta-analyses, although this is reported in Tables 1a and 1b. It might be that longer walking duration is a better predictor of physical activity outcomes, and this could be established through meta-regression. However, we chose not to conduct meta-regression because of the wide variation in physical activity outcome measures used in the included studies, and because there were only nine studies that could contribute to the calculation. In addition, some of the studies included warming up and cooling off, whereas others did not report this. These times are often opportunities for social interaction, which would not be captured if duration of exercise was used only. Social connectedness outcome measures were not well reported, and the measures used were not well validated.

\section{Implications for Policy}

This systematic review aims to inform public policy on group walking promotion. As high levels of moderate intensity physical activity (60 to $75 \mathrm{~min}$ per day) seem to eliminate any increased risk of death associated with lack of physical activity, the more that people can be encouraged to undertake physical activity, the better it will be for them, the health services and the public purse $(46 ; 47)$. The lack of strong evidence demonstrating that group walking participation enhanced physical activity compared with walking alone means that there is no strong driver as yet for governments to adopt coherent strategic plans or to invest in this area of physical activity behavior change. Walking in groups is a safe and inexpensive intervention that can be delivered easily and successfully in the community and has consistency with expectations and the public's perception of walking.

\section{Implications for Research}

There needs to be further research clearly evaluating the benefits for physically healthy people in taking part in group walking compared with walking alone, particularly measuring physical activity over the longer term. The activity measure should be that recommended by the World Health Organization, that is, the proportion meeting the physical activity guidelines. Other outcomes should include generic quality of life and wider societal costs. Capturing any adverse events is also important. There also needs to be evaluation of the best ways to motivate people to continue with walking once the initial enthusiasm wanes and the officially organized activity is discontinued. It is possible that sociable aspects of group walking may enhance persistence in maintaining physical activity participation.

There needs to be encouragement to the physical activity research community to standardize physical activity measurement (following the COMET initiative) (48), so that all studies measure physical activity consistently. This would enable results of various interventions to be compared across studies.

\section{CONCLUSIONS}

The bulk of the empirical evidence base for walking in groups consists of small studies comparing this activity to inactive controls and there is good evidence that walking in groups is more effective than inactivity. However, there is far less evidence on walking in groups compared with walking alone, yet research has shown that exercise adherence is enhanced through the use of social support. At a time when we are being encouraged to meet physical activity guidelines, a large proportion of the public fail to do so. Better quality evidence may encourage government policy to promote walking in groups organized by the groups themselves. Adequately powered multi-center RCTs along with qualitative process evaluation should be undertaken to test the efficacy of walking group encouragement interventions.

\section{SUPPLEMENTARY MATERIAL}

Supplementary Table 1: https://doi.org/10.1017/S0266462317001088 Supplementary Figure 2: https://doi.org/10.1017/S0266462317001088 Supplementary Table 2: https://doi.org/10.1017/S0266462317001088 Supplementary Figure 2: https://doi.org/10.1017/S0266462317001088 Supplementary Table 3: https://doi.org/10.1017/S0266462317001088 Supplementary Table 4: https://doi.org/10.1017/S0266462317001088 Supplementary Figure 3: https://doi.org/10.1017/S0266462317001088

\section{CONFLICTS OF INTEREST}

No conflicts of interest for C. Meads or J. Exley. 


\section{REFERENCES}

1. World Health Organization. Global Strategy on Diet, Physical Activity and Health Physical activity and adults. http://www.who.int/ dietphysicalactivity/factsheet_adults/en/ (accessed September 22, 2016).

2. World Health Organization. Global recommendations of physical activity for health. http://apps.who.int/iris/bitstream/10665/44399/1/ 9789241599979_eng.pdf (accessed September 22, 2016).

3. Centers for Disease Control and Prevention. National Center for Health Statistics. Exercise or physical activity. http:/www.cdc.gov/nchs/ fastats/exercise.htm accessed (accessed September 22, 2016).

4. Statistics Canada. Directly measured physical activity of adults, 2012 and 2013. http://www.statcan.gc.ca/pub/82-625-x/2015001/article/ 14135-eng.htm (accessed September 22, 2016).

5. Australian Government Department of Health. Research and statistics. This page contains scientific evidence review reports and key facts and figures regarding physical activity and sedentary behaviour. http://www.health.gov.au/internet/main/publishing.nsf/content/ health-pubhlth-strateg-active-evidence.htm (accessed September 22, 2016).

6. Townsend N, Wickramasinghe K, Williams J, Bhatnagar P, Rayner M. Physical Activity Statistics 2015. British Heart Foundation: London; 2015.

7. Gidlow C, Johnston LH, Crone D, James D. Attendance of exercise referral schemes in the UK: A systematic review. Health Educ J. 2005;64:168-186.

8. Stiggelbout M, Hopman-Rock M, Crone M, Lechner L, van Mechelen W. Predicting older adults' maintenance in exercise participation using an integrated social psychological model. Health Educ Res. 2006;21:114.

9. Wing RR, Jeffery RW. Benefits of recruiting participants with friends and increasing social support for weight loss and maintenance. $J$ Consult Clin Psychol. 1999;67:132-138.

10. Campbell F, Holmes M, Everson-Hock E, et al. A systematic review and economic evaluation of exercise referral schemes in primary care: A short report. Health Technol Assess. 2015;19:1-110.

11. Farrance C, Tsofliou F, Clark CJ. Evaluating the views of participants and adherence rates of community based group exercise interventions: A mixed methods systematic review. Physiotherapy. 2015;101(Supp1 1): $\mathrm{e} 374-\mathrm{e} 375$

12. De Moor D. Walking for health. London: The Ramblers Association; 2013.

13. Lee IM, Buchner DM. The importance of walking to public health. Med Sci Sports Exerc. 2008;40(Suppl):S512-S518

14. Milton K, Grix J. Public health policy and walking in England Analysis of the 2008 'policy window'. BMC Public Health. 2015;15: 614.

15. Anon. Before, during and after: Making the most of the London 2012 Games. London: UK Government Department for Culture, Media and Sport; 2008. http://webarchive.nationalarchives.gov.uk/+/http: /www.culture.gov.uk/images/publications/2012LegacyActionPlan.pdf (accessed October 13, 2016).

16. U.S. Department of Health and Human Services. Surgeon General.gov. Active living. http:/www.surgeongeneral.gov/priorities/prevention/ strategy/active-living.html (accessed September 22, 2016).

17. U.S. Department of Health and Human Services. Step it up! The Surgeon General's call to action to promote walking and walkable communities. Washington, DC: U.S. Department of Health and Human Services, Office of the Surgeon General; 2015

18. U.S. Department of Health and Human Services. Surgeon General.gov. National Prevention Strategy. http://www.surgeongeneral.gov/priorities/ prevention/strategy/index.html\#The Priorities (accessed September 22, 2016).
19. Hanson S, Jones A. Is there evidence that walking groups have health benefits? A systematic review and meta-analysis. Br J Sports Med. 2015;49:710-715

20. Kassavou A, Turner A, French DP. Do physical interventions to promote walking in groups increase physical activity? A meta-analysis. Int $J \mathrm{Be}$ hav Nutr Phys Act. 2013;10:18

21. Blank L, Jones R, Buckley Woods H, Payne N. Systematic review and narrative synthesis of the effectiveness of local interventions to promote cycling and walking for recreational and travel purposes. Sheffield: University of Sheffield, School of Health and Related Research; 2012.

22. Higgins JPT, Green S, eds. Cochrane handbook for systematic reviews of interventions, Version 5.1.0 [ updated March 2011]. London: The Cochrane Collaboration; 2011

23. Avila P, Hovell MF. Physical activity training for weight loss in Latinas: A controlled trial. Int J Obes Relat Metab Disord. 1994;18:476-482 (referenced in Blank L, Jones R, Woods HB, Payne N. Systematic review and narrative review of the effectiveness of local interventions to promote cycling and walking for recreational and travel purposes. Sheffield: ScHARR University of Sheffield; 2012. https://www.nice.org.uk/ guidance/ph41/evidence/effectiveness-revew-430261597 (accessed August 24, 2016).

24. Fisher KJ, Li F. A community-based walking trial to improve neighbourhood quality of life in older adults: A multilevel analysis. Ann Behav Med. 2004;28:186-194.

25. Gusi N, Reyes MC, Gonzalez-Guerrero JL, Herrera E, Garcia JM. Costutility of a walking programme for moderately depressed, obese or overweight elderly women in primary care: A randomised controlled trial. BMC Public Health. 2008;8:1-10.

26. Hamdorf PA, Penhall RK. Walking with its training effects on the fitness and activity patterns of 79-91 year old females. Aust $N Z \mathrm{~J} \mathrm{Med}$. 1999;29:22-28

27. Isaacs AJ, Critchley JA, See Tai S, et al. Exercise evaluation randomised trial (EXERT): A randomised trial comparing GP referral for leisure centre-based exercise, community based walking and advice only. Health Technol Assess. 2007;11:10.

28. Jancey JM, Lee AH, Howat PA, Clarke A, Wang K, Shilton T. The effectiveness of a physical activity intervention for seniors. Am J Health Promot. 2008;22:318-321.

29. Krieger J, Rabkin J, Sharify D, Song L. High point walking for health: Creating built and social environments that support walking in a public housing community. Am J Public Health. 2009;99(Supp 3): S593-S599.

30. Kriska AM, Bayles C, Cauley JA, et al. A randomised exercise trial in older women: Increased activity over two years and the factors associated with compliance. Med Sci Sports Exerc. 1986;18:557-562.

31. Lamb SE, Bartlett HP, Ashley A, Bird W. Can lay-led walking programmes increase physical activity in middle aged adults? A randomised controlled trial. J Epidemiol Community Health. 2002;56:246-252.

32. Maki Y, Ura C, Yamaguchi $\mathrm{T}$, et al. Effects of intervention using a community-based walking programme for prevention of mental decline: A randomised controlled trial. J Am Geriatr Soc. 2012;60:505510 .

33. Moore-Harrison TL, Speer EM, Johnson FT, Cress E. The effects of aerobic training and nutrition education on functional performance in low socioeconomic older adults. J Geriatr Phys Ther. 2008;31:18-23.

34. Palmer LK. Effects of a walking program on attributional style, depression and self-esteem in women. Percept Mot Skills. 1995;81:891-898.

35. Resnick B. Testing the effect of the WALC intervention on exercise adherence in older adults. J Gerontol Nurs. 2002;28:40-49.

36. Takahashi M, Miyashita M, Kawanishi N, et al. Low volume exercise training attenuates oxidative stress and neutrophils activation in older adults. Eur J Appl Physiol. 2013;113:1117-1126. 
37. Cox KL, Burke V, Beilin LJ, et al. Short and long-term adherence to swimming and walking programs in older women - The sedentary women exercise adherence trial (SWEAT-2). Prev Med. 2008;46: 511-517.

38. Lee CY, Lee H, Jeon KM, Hong YM, Park SH. Self-management program for obesity control among middle-aged women in Korea: A pilot study. Jpn J Nurs Sci. 2011;8:66-75.

39. Nguyen M-N, Gauvin L, Martineau I, Grignon R. Promoting physical activity at the community level: Insights into health promotion practice from the Laval Walking club's perspective. Health Promot Pract. 2002;3:485-496.

40. Thomas GN, MacFarlane DJ, Guo B, et al. Health promotion in older Chinese: A 12-month cluster randomized controlled trial of pedometry and "peer support". Med Sci Sport Exerc. 2012;44:1157-1166.

41. Pereira MA, Kriska AM, Day RD, et al. A randomised walking trial in postmenopausal women. Effects on physical activity and health 10 years later. Arch Intern Med. 1998;158:1695-1701

42. NHS Choices. Physical activity guidelines for adults. http://www.nhs.uk/ Livewell/fitness/Pages/physical-activity-guidelines-for-adults.aspx (accessed September 26, 2016).
43. Coleman RJ, Kokolakakis T. Ramchandani G. Walking for Health Attendance Study. Natural England Commissioned Reports, Number 098. Sheffield: Sports Industries Research Centre (SIRC); 2011.

44. Waters L, Reeves M, Fjeldsoe B, Eakin E. Control group improvements in physical activity intervention trials and possible explanatory factors: A systematic review. J Phys Act Health. 2012;9:884-895.

45. Caspersen CJ, Powell KE, Christenson GM. Physical activity, exercise, and physical fitness: Definitions and distinctions for health-related research. Public Health Rep. 1985;100:126-131.

46. Ekelund U, Steene-Johannessen J, Brown WJ, et al. Does physical activity attenuate, or even eliminate, the detrimental association of sitting time with mortality? A harmonised meta-analysis of data from more than 1 million men and women. Lancet. 2016;388:1302-1310.

47. Ding D, Lawson KD, Kolbe-Alexander TL, et al. The economic burden of physical inactivity: A global analysis of major non-communicable diseases. Lancet. 2016;388:1311-1324.

48. Williamson P, Clarke M. The COMET (Core Outcome Measures in Effectiveness Trials) Initiative: Its role in improving Cochrane reviews. Cochrane Database Syst Rev. 2012;5:ED000041. 